\title{
Myomectomy during cesarean section: is it a contraindication these days?
}

\author{
Amit Gupta ${ }^{1 *}$, Anju Vij ${ }^{1}$, Tanu Verma ${ }^{1}$, Molly ${ }^{1}$, Rajinder Kumar ${ }^{1}$, Bharti Gupta ${ }^{2}$
}

\author{
${ }^{1}$ Department of Obstetrics and Gynecology, DRPGMC, Kangra (Tanda), Himachal Pradesh, India \\ ${ }^{2}$ Department of Anesthesia, DRPGMC, Kangra (Tanda), Himachal Pradesh, India
}

Received: 19 April 2020

Accepted: 29 May 2020

\section{*Correspondence:}

Dr. Amit Gupta,

E-mail:dramit203@gmail.com

Copyright: (C) the author(s), publisher and licensee Medip Academy. This is an open-access article distributed under the terms of the Creative Commons Attribution Non-Commercial License, which permits unrestricted non-commercial use, distribution, and reproduction in any medium, provided the original work is properly cited.

\begin{abstract}
Myomectomy during the cesarean section is a debatable procedure because of raised risk of associated uncontrollable hemorrhage and postoperative morbidity. 38 years, elderly primigravida, who conceived after primary infertility with large leiomyoma in the lower uterine segment, underwent myomectomy during the cesarean section. Her intraoperative hemorrhage was within normal limits and post-partum period was uneventful. Conclusion of this study is Safety and feasibility of myomectomy along with cesarean largely depends upon the case selection, experience of the obstetrician and backup ICU and transfusion facilities.
\end{abstract}

Keywords: Cesarean section, Leiomyoma, Myomectomy

\section{INTRODUCTION}

Leiomyoma originating from the smooth muscle layer of uterus, is the most common benign tumor responsible for a major cause of morbidity in women of a reproductive age.$^{1-4}$ Leiomyoma complicating pregnancy or pregnancy complicating leiomyoma, as pain, uterine bleeding, infertility, spontaneous abortion, malpresentation, preterm delivery and placental abruption, are frequently encountered by the obstetrician in day-today clinical practice these days. ${ }^{5,6}$ Uterine leiomyoma is found in approximately $2 \%$ of pregnant women and this association has mainly been seen in elderly primigravidas. $^{7,8}$

Myomectomy is the least common surgical operation performed during cesarean section. A study, that reviewed 10 years of experience, it was only observed in $0.89 \%$ of all cesarean sections. ${ }^{9}$ Myomectomy during cesarean section was practically absent from the obstetric literature until the last decade and it was usually suggested to postpone and perform it before the next pregnancy. Myomectomy along with cesarean increases the probability of hemorrhage by about $10 \%$, while at the same time it can avoid second surgery. ${ }^{10}$ Disputes on the myomectomy during the cesarean section as the procedure may raise the concerns about uncontrollable hemorrhage, which brings about the necessity of hysterectomy and even elevation of postoperative morbidity, where as some studies indicate that surgical management of uterine fibroid at cesarean section may be a safe option with careful case selection. ${ }^{11-13}$

\section{CASE REPORT}

\section{Case history}

A 38 years old elderly primigravida at period of gestation 34 weeks 4 days, who conceived after primary infertility with large leiomyoma, was referred to Dr. RPGMC Kangra at Tanda. On detailed history, patient had conceived spontaneously after 13 years of marriage and had irregular antenatal visits at the referral end hospital. Patient was $\mathrm{Rh}$ negative and her all other routine antenatal investigations were within normal limits. Patient developed pain lower abdomen at 34 weeks 3 
days for which she had an ultrasound, which confirmed a large lower uterine segment (LUS) fibroid with dimensions of 10X8X5 cm with marginal hematoma. Her earlier antenatal ultrasound records were not available with her.

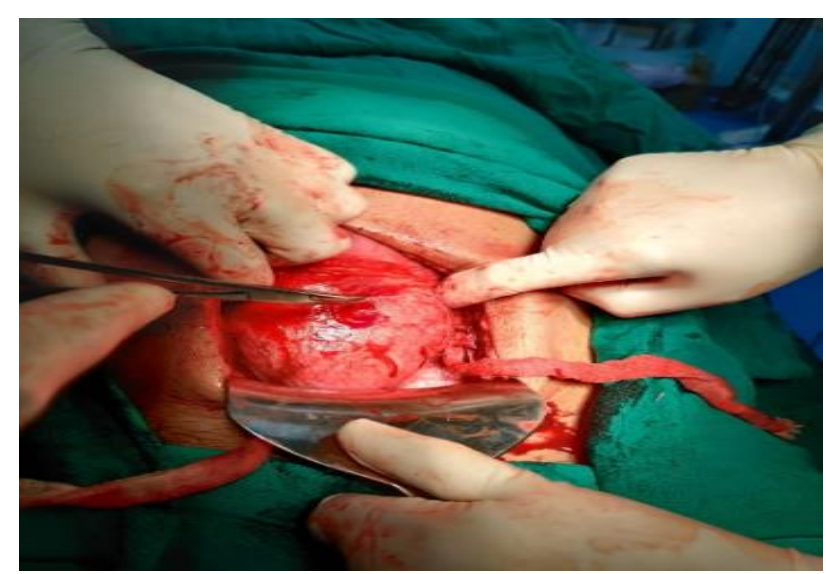

Figure 1: Initial incision.

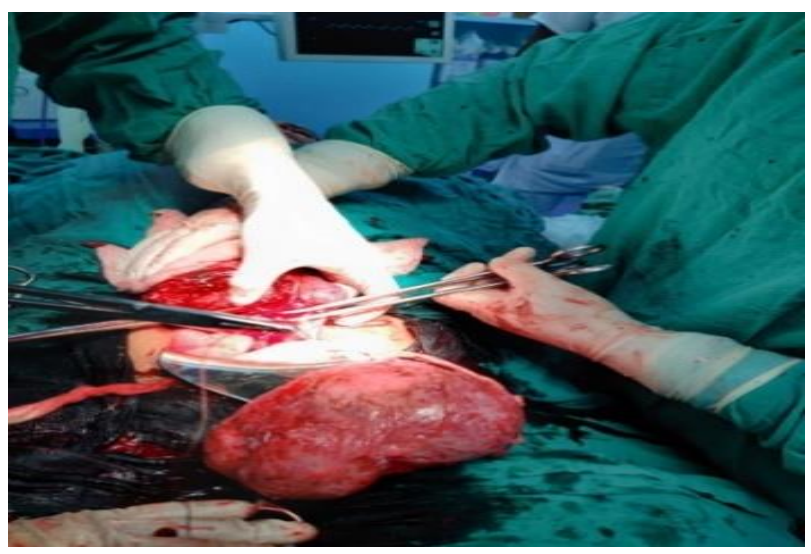

Figure 2: Extracted myoma.

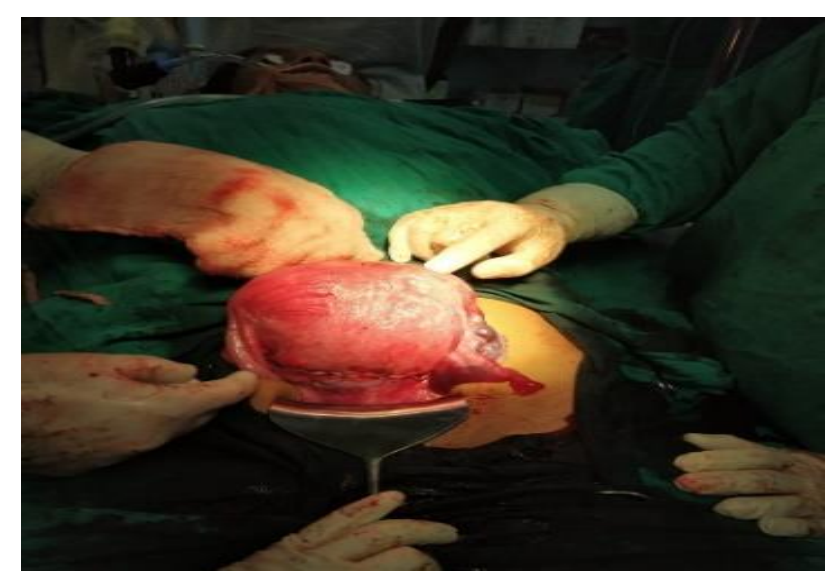

Figure 3: Uterus after closure.

\section{Examination and management}

Patient was stable and on per abdomen examination, uterus was 36 weeks size, relaxed with FHS present
$(122 / \mathrm{min})$ and a mass of $10 \times 7 \mathrm{~cm}$ was palpable on the right side of lower abdomen. On per vaginal examination, cervix was pulled up, uneffaced, and internal os was closed. Station of head was high up.

For fetal well-being, non-stress test was done which was nonreactive. A repeat ultrasound was done at our institute in which, lower uterine fibroid of size $\sim 10$ X7X6 cm along with anhydramnios was diagnosed. Patient was planned for emergency cesarean section for low modified biophysical score with precious pregnancy.

After consultation with anesthesiologist and making other preoperative arrangements like blood, emergency investigations etc. cesarean section was performed. The abdomen was opened with vertical midline incision. A large fibroid of 10X7X6 cm covering the lower uterine LUS was present (Figure 1). After pushing down of the bladder, the lower segment of the uterus was incised. The incision was extended laterally with fingers, a bit cephalad due to the huge myoma and myomectomy was completed with blunt and sharp dissection (Figure 2). A male baby, weighing $2700 \mathrm{gm}$. was extracted out after rupturing the membranes. Prophylactic injection methylergonovine $0.2 \mathrm{mg} \mathrm{I} / \mathrm{v}$ (methergine) was given and after removal of the placenta high dose oxytocin (40 IU $/ 1000 \mathrm{cc}$. ringer lactate) infusion was started. Uterus was stitched in three layers (Figure 3) and abdomen was closed in layers after ensuring complete hemostasis.

\section{Outcome}

The Apgar score of the newborn was 8 at the first minute. Fibroid extracted was measuring about $10 \times 7 \times 6 \mathrm{~cm}$ in size and weighting 1000 grams. The amount of hemorrhage was approximately $1500 \mathrm{cc}$. The duration of operation was 90 minutes. One-unit whole blood was transfused in the postoperative period. Post-operative period remained uneventful and the patient was discharged on 5th day after surgery.

\section{DISCUSSION}

Recently, uterine leiomyomas are more frequently encountered during pregnancy because of late marriages and delayed conception till late thirties. ${ }^{14}$ In clinical practice, obstetricians have to make a wise decision on whether to remove the fibroids during cesarean section or not. Conventionally, myomectomy is not recommended as a routine procedure for those undergoing cesarean section as it may induce perioperative complications, especially the excessive hemorrhage that may result in an emergency hysterectomy. ${ }^{15-17}$ But myomectomy during cesarean section, sometimes, may become inevitable, as in this case, and requires adequate surgical expertise, judicious use of prophylactic oxytocics and a vigilant postoperative monitoring. It can be performed in a tertiary care unit with reasonable safety and is not absolutely contraindicated these days. 


\section{CONCLUSION}

Myomectomy during cesarean section can be performed in selected cases. Though it increases the risk of perioperative hemorrhage and cesarean hysterectomy yet, in inevitable circumstances, it can be performed, in wellequipped hospital having blood transfusion facilities, with an acceptable risk by experienced obstetricians.

Funding: No funding sources

Conflict of interest: None declared

Ethical approval: Not required

\section{REFERENCES}

1. Gupta A, Thakur S, Verma S, Gupta B. Incidental myomectomy along with cesarean section: a case report. Obs Gynae Today. 2004;9(2):80-1.

2. Kolankaya A, Arici A. Myomas and assisted reproductive technologies: when and how to act? Obstet Gynecol Clin North Am. 2006;33(1):145-52.

3. Klatsky PC, Tran ND, Caughey AB, Fujimoto VY. Fibroids and reproductive outcomes: a systematic literature review from conception to delivery. Am $\mathbf{J}$ Obstet Gynecol. 2008;198(4):357-66.

4. Qidwai GI, Caughey AB, Jacoby AF. Obstetric outcomes in women with sonographically identified uterine leiomyomata. Obstet Gynecol. 2006;107(2):376-82.

5. Lam SJ, Best S, Kumar S. The impact of fibroid characteristics on pregnancy outcome. Am J Obstet Gynecol. 2014;211(4):391-5.

6. Stout MJ, Odibo AO, Graseck AS, MacOnes GA, Crane JP, Cahill AG. Leiomyomas at routine secondtrimester ultrasound examination and adverse obstetric outcomes. Obstet Gynecol. 2010;116(5):1056-63.

7. Katz VL, Dotters DJ, Droegemeuller W. Complications of uterine leiomyomas in pregnancy. Obstet Gynecol. 1989;73:593-6.

8. Depp R. Cesarean delivery. In: Obstetrics: normal and problem pregnancies $4^{\text {th }}$ edition. Edited by: Gabbe SG, Niebyl JR, Simpson JL. New York: Churchill Livingstone; 2002:599.
9. Baloniak B, Jasinskil O, Prews K. Slomko Z. Morphologic pattern of uterine myomas enucleated at cesarean section. Clinical Pol. 2002;73(4):255-9.

10. Kwawukume EY. Myomectomy during cesarean section. Int J Gynecol Obstet. 2002;76:183-4.

11. Pergialiotis V, Sinanidis I, Louloudis E, Vichos T, Perrea DN, Doumouchtsis SK. Perioperative complications of cesarean delivery myomectomy: a meta-analysis. Obstet Gynecol. 2017;130(6):1295303.

12. Hatırnaz S, G“uler O, Bas S, Tokg”oz AC, Kilıc GS. Endometrial myomectomy: a novel surgical method during cesarean section. The J Maternal-Fetal Neonat Med. 2017;31(4):433-8.

13. Turgal M, Ozgu-Erdinc AS, Beksac K, Ozyuncu O, Karaagaoglu E, Beksac MS. Myomectomy during cesarean section and adhesion formation as a longterm postoperative complication. Ginekologia Polska. 2015;86(6):457-60.

14. Kant A, Manuja S, Pandey R. Cesarean myomectomy. J Obstet Gynecol India. 2007;57(2):128-30.

15. Islam MS, Ciavattini A, Petraglia F, Castellucci M, Ciarmela P. Extracellular matrix in uterine leiomyoma pathogenesis: a potential target for future therapeutics. Human Reprod Update. 2018;24(1):5985.

16. Velasco VR. Update of the conservative management of the uterine leiomyomata. Analesdela Real Academia Nacional de Medicina. 2006;123(4):841-62.

17. Okogbo FO, Ezechi OC, Loto OM, Ezeobi PM. Uterine leiomyomata in South Western Nigeria: a clinical study of presentations and management outcome. African Health Sci. 2011;11(2):271-8.

Cite this article as: Gupta A, Vij A, Verma T, Molly, Kumar R, Gupta B. Myomectomy during cesarean section: is it a contraindication these days?. Int J Reprod Contracept Obstet Gynecol 2020;9:3090-2. 